\title{
Causes of pattern in plant communities where environmental change is rapid and species longevity is short
}

\author{
Cousens, Roger D. ${ }^{1 *}$; Dale, Mark R.T.2; Taylor, James ${ }^{3}$; Law, Richard ${ }^{4}$; \\ Moerkerk, Michael ${ }^{5} \&$ Kembel, Steven W. ${ }^{2}$
}

\author{
${ }^{1}$ School of Resource Management, Burnley Campus, The University of Melbourne, 500 Yarra Boulevard, Richmond, VIC \\ 3121, Australia; ${ }^{2}$ Department of Biological Sciences, University of Alberta, Edmonton, Alberta, T6G 2E9, Canada; \\ ${ }^{3}$ Australian Centre for Precision Agriculture, McMillan Building A05, The University of Sydney, NSW 2006, Australia; \\ ${ }^{4}$ Biology Department, University of York, P.O. Box 373, York YO10 5YW, UK; ${ }^{5}$ Department of Primary Industries, \\ Victorian Institute of Dryland Agriculture, P.O. Box 260, VIC 3401, Australia; \\ *Corresponding author; E-mail rcousens@unimelb.edu.au
}

\begin{abstract}
.
Questions: To what extent can spatial structure and its causes be determined in a highly disturbed environment? What are the main determinants of pattern and are these species-specific? How much do spatial patterns change over generations?

Location: Wimmera region of southern Australia.

Methods: Broad-leaved weeds were counted in 225000 contiguous $20-\mathrm{cm}$ square quadrats. A substantial number of these quadrats were recorded again after two and four years. An hierarchical 'adaptive analysis' approach was used to select spatial analytical methods to examine specific aspects of pattern and variation in pattern from year to year.

Results: Patterns varied among species and included both dense and sparse patches surrounded by areas of zero density, diffuse gradations of density and clear anisotropy. Patterns in Erodium botrys and Oxalis pes-caprae persisted over years, whereas patterns in Arctotheca calendula were less pronounced and varied over time. Edaphic factors appeared to have only a minor influence over the spatial distribution of the weed community as a whole. In Oxalis pes-caprae, whose patches were hypothesized to have been shaped by cultivation, there was no spread in four years, despite further tillage. Outlying plants of $O$.pes-caprae failed to establish new patches, even in the year of greatest population increase. Little evidence of localised recruitment events was found.

Conclusions: Despite repeated annual disturbances by natural and anthropogenic mechanisms, clear and interpretable spatial structure develops in annual weeds over a range of spatial resolutions. Adaptive analysis is a useful approach to the characterization of such patterns.
\end{abstract}

Keywords: Adaptive analysis; Annual; Disturbance; Patch; Seedling; Soil; Spatial analysis; Tillage.

Nomenclature: Walsh \& Entwisle (1994-1999).

Abbreviations: $E C_{\mathrm{e}}=$ Electrical conductivity; $E C_{a}=$ Apparent electrical conductivity; DTM = Digital Terrain Model.

\section{Introduction}

The aim of much of vegetation science, and indeed of ecology in general, is to deduce the processes that have led to the particular patterns that we see in nature. Some of the earliest ecological research involved the description of species zonation on geographic and topographic scales, for which the processes were very obvious. In much of plant community ecology, we still tend to study systems in which edaphic variation across the target area is considerable and in which perennials dominate. The temporal duration of stability of the environment in comparison with the generation times of plants is such that the vegetation has had time to approach an equilibrium and thus to correspond closely to the local microclimatic, soil or hydrological conditions. Moreover, the long return times for major perturbations also mean that interactions between species have time to develop and hence lead to the superimposition of patterns resulting from biological interactions on to those caused directly by abiotic conditions. However, the spatial dynamics of perennial systems will often be so slow that it may be difficult to observe the causative dynamic processes within these systems directly (except in the instance of a recent major perturbation). The result is that we both expect and observe clear patterns in the vegetation, but we must infer underlying processes from a temporal 'snap shot'.

Not all environments and their communities are stable. In some habitats, environmental perturbations recur at frequent and often regular intervals. Such highly disturbed environments favour species with short life cycles, so that ephemeral, annual and biennial species feature strongly in desert floras and in Mediterranean climates (Crawley 1997), while many cropping systems are characterised almost exclusively by annuals. It is to be expected that species in these habitats will be less able to equilibrate with spatial edaphic variation than in 
more stable situations. Interactions between species will also develop less intensely. Dispersal into a vacant habitat will occur frequently, allowing progeny to 'escape' from interactions with other species, while environmental variation may cause species dominance hierarchies to change repeatedly over time.

High levels of disturbance (temporally-dependent environmental variation), however, do not necessarily preclude the development of spatial structure in vegetation. Annual weeds in annually-disturbed cropping systems, for example, commonly occur in patches and these can remain relatively fixed in position over time (Wilson \& Brain 1991). While long-term spatial habitat attributes still exist, spatially-dependent dispersal, recruitment and mortality may also be commonly linked to the disturbance events themselves (Cousens \& Mortimer 1995). In the case of crop management in fields of simple shapes and when using 'tramlines' (consistent tracks followed by spraying vehicles), spatially-dependent demography and dispersal may be highly predictable from year to year. Alternatively, events may occur sporadically, only in some years and in some parts of a field. For example, random patches of plants may sometimes be missed by herbicide sprayers while waterlogging may recur irregularly but consistently in the same places. Hence, there is the potential for certain years to act as 'spatial filters' or as pattern enhancers that dictate pattern strongly in future years, but within the time-frame of observations the causes may not be apparent. Making things even more difficult for the observer, the many spatial and temporal factors may interfere with one another, each acting at different scales, and leading to complex patterns that may not have a single, direct or obvious cause. The spatial patterns in disturbed plant populations will necessarily be much fuzzier than in less disturbed habitats and in vegetation dominated by perennials. It is also likely to be quite difficult to elucidate processes from 'snap shots' of patterns.

The suite of tools available for us to identify controlling processes in these systems is largely the same as that for more stable systems. We can, for example, measure spatial autocorrelation methods to categorise pattern (Dale et al. 2002), while multivariate analyses can be used to estimate relationships between variables (Legendre \& Legendre 1998). We can look for spatial 'signatures' that reflect some processes but not others: for example, machinery traffic can lead to regular, anisotropic patterns that will be revealed by directional correlograms. The short life-spans of the species and the short durations of the causative processes may also be used to our advantage. For example, it is possible to map vegetation over a number of generations and to interpret the changes with respect to factors that vary over short time frames. Although it will not be possible to record the spatial and temporal occurrences of every variable, we are more likely to detect the effects of causal processes soon after their occurrence.

The objective of this study was to examine the extent to which spatial structure and its causes can be determined in a highly disturbed environment. Specifically, what attributes of the patterns can be revealed, how much do the patterns change over generations, what are the main determinants of pattern, and are these speciesspecific? Importantly for future studies, are the analytical methods used successfully for more stable systems sufficient to characterise pattern and process in a highly disturbed system? We chose a case study of a cropping field in a mediterranean climate, i.e. a habitat that is subject to strong temporal variation (in water - see Ridge 1986 - and in management practices) and in which there are multiple temporally-variable causes of spatially-dependent demography and dispersal. We collected data from contiguous $20 \mathrm{~cm} \times 20 \mathrm{~cm}$ quadrats covering 0.9 ha, which allowed us to examine pattern over a wide range of spatial scales appropriate to many of the demographic and dispersal processes likely to be acting within the field.

\section{Methods}

\section{Data collection}

The study site is in the Wimmera region of Victoria, Australia, near the town of Noradjuha. The topsoil is a sandy loam, with gravel and stones in some patches and with a clay subsoil. For many years, the field had been in a rotation of pasture, based on Trifolium subterraneum and Triticum aestivum. During the period of study, 19982003, the rotation sequence was Triticum, pasture, Brassica napus, Triticum, Hordeum vulgare and pasture.

The choice of quadrat size is somewhat arbitrary and the resulting 'grain size' places a lower limit on the processes that can be detected. A quadrat size of $20 \mathrm{~cm}$ $\times 20 \mathrm{~cm}$ was chosen, corresponding roughly with the sizes of rosettes of the species studied. The majority of seeds from the species would naturally be dispersed within a radius of perhaps 3-5 quadrats (Cousens \& Mortimer 1995), hence this quadrat size would allow the detection of localised clustering due to this process. Mapping took place from 22-26.06.1998, 19-23.06. 2000 and 29.07-01.08.2002, when the cereal crops were at the three-leaf stage (or B. napus at the 3-4 leaf stage) and few new weed seedlings were appearing. A $100 \mathrm{~m}$ by $90 \mathrm{~m}$ area was marked with string into $5 \mathrm{~m}$ wide strips in the east-west direction. A rigid frame, $5 \mathrm{~m}$ wide and divided into two rows of twenty-five $20 \mathrm{~cm}$ by $20 \mathrm{~cm}$ quadrats, was placed across a strip and moved forward after plants 
were counted. Five observers recorded the number of plants in blocks of ten quadrats along the frame; recorders changed position after each strip. In this way, four species were recorded for each of 225000 quadrats in 1998. Counting took five days, during which time further seedling emergence was not apparent. In 2000 and 2002, a reduced area was mapped, at the northeast corner of the 1998 area, sufficient to compare species distributions within a $45 \mathrm{~m} \times 75 \mathrm{~m}$ sub-area ( $0.34 \mathrm{ha})$.

The residual weed community at the time of mapping in 1998 (i.e. those species surviving herbicide application) consisted mostly of Lolium rigidum, Avena fatua, Erodium botrys, Arctotheca calendula, Acetosella vulgaris, Buglossoides arvense and Oxalis pes-caprae. Only the broad-leaved species were counted, for reasons of operational ease (distinction between grasses and cereals slows down counting considerably) and because the farmer actively manages grass populations using selective herbicides that begin to work prior to the optimum time for counting broad-leaved species. In contrast, broad-leaved herbicides tend to be applied later.

In 2000, most of the same species were again present. There were sufficient numbers of Erodium cicutarium to warrant mapping, but no $B$. arvense. In 2002, there were very few $E$. cicutarium and a small number of $B$. arvense. Large numbers of Crassula spp. seedlings were seen, but recording was not feasible because of the extraordinarily high density and because many seedlings were still emerging. There were also small numbers of Malva parviflora, Cirsium vulgare, Sonchus oleraceus and various other Asteraceae.

Of the five species sufficiently abundant for analysis (A. calendula, E. botrys, E. cicutarium, B. arvense and $O$. pes-caprae), only $B$. arvense seeds are recorded as being taken up into combine harvesters (Moerkerk 2002) and some of its seeds dispersed in that way; $O$. pescaprae reproduces only vegetatively and is thus mainly spread by cultivation; while E. botrys and E. cicutarium disperse explosively.

Data were entered into a spreadsheet; a Fortran (DIGITAL ${ }^{\mathrm{TM}}$ Equipment Corporation) program was written to combine the original quadrat counts into larger quadrats of a given size and shape required by the particular analysis. Data are available by request from the corresponding author.

\section{Approach to spatial data analysis}

The question of how to analyse spatial pattern, in any system, is far from trivial. Ecologists have access to an ever-increasing number of methods for analysing spatial data (e.g. Cressie 1991; Dale 1999; Perry et al. 2002). Existing techniques are modified, perhaps renamed according to the field of application, only to go out of favour as new approaches gain in popularity. Rather than making previous methods redundant, the new methods should be seen as adding to our methodological tool box, so that we can advance ecological understanding more effectively. How does the practitioner then choose from this (now packed) tool box? Comparisons of a range of methods to common data sets (e.g. Cullinan \& Thomas 1992; Perry et al. 2002) tend to conclude that a number of different methods should be applied to each data set, since each method tells us slightly different things. Making the choice more complicated is the fact that many of the techniques are related mathematically and conceptually (Dale et al. 2002), resulting in a lack of independence of the information obtained from different methods.

Spatial data analysis should be designed around the scientific aims of the research. This may seem obvious, but the objective of many spatial vegetation studies often appears to be a simple description of spatial distribution, and a single method is often the sole basis for interpretation of all species. What is it specifically that the researcher wants to know? For example, even though autocorrelation techniques can be applied to data from large, widely-spaced quadrats and the results used to derive correlograms, the biology of the target organism/community and the processes of interest should dictate both the scale of observation and the analysis employed (Dungan et al. 2002). Only in this way can we efficiently address the key ecological questions relating pattern and process.

In this paper we use an hierarchical approach to spatial analysis, which we suggest should be termed 'adaptive analysis' (analogous to 'adaptive sampling' strategies), in which the data are explored systematically according to (1) the questions of interest to the particular researcher, and (2) the specific properties of the data. By looking at maps of the raw data, we ask questions and raise hypotheses about specific aspects of the apparent pattern. The answer to one question will determine subsequent questions, and hence the sequence of analytical methods chosen. (We are aware that the term 'adaptive analysis' is used in other branches of science in a slightly different context, but we consider that it is the most appropriate term to communicate the essence of our approach to ecologists). For each project/ location/species, a flow-chart can be constructed and the analytical methods selected appropriately as each step through the chart is determined (see Fig. 1; cf. Fortin \& Dale 2005). In this particular project, the overall scientific questions are: what form of structure is represented; is this structure stable over time; and hence can hypotheses be raised about the controlling processes? The testing of these hypotheses may require the acquisition of additional data in the future, and the addition of further lines on the flow chart. 


\section{Analytical methods}

\section{Is there spatial structure? (Fig. 1A)}

It is usual to begin spatial data exploration by examining whether the observed distribution departs significantly from a random distribution. This does not imply that we would necessarily accept a null hypothesis that data are distributed at random. A truly random spatial distribution is likely to be highly unusual: it is hard to think of any processes that could distribute plants at random at all scales. Although some processes lead towards greater aggregation and others lead to greater regularity (Wiegand et al. 2000), the net effect is unlikely to be completely random. The pattern may be weak, as a result of stochastic and dynamic events, and we may measure it only imperfectly through our sampling regime and measurement errors in the data. Significant departure from a random distribution is therefore used as a threshold for deciding whether further data exploration is likely to be rewarded.

We employed a 'joins' test to determine departure from a random distribution (Pielou 1977). Aggregation will result in quadrats of high plant density, or of low density, occurring more often together than expected by chance. Each quadrat was scored as High $(\mathrm{H})$ or Low (L), according to whether the density of the species in question was above or below the median for the year. All possible adjacent pairs of quadrats were compared (in all directions, with eight 'King's move' neighbours) to determine the total number of pairs that were $\mathrm{H}-\mathrm{H}$ or L-L. The data set, at this particular quadrat size, was then completely randomized and the number of $\mathrm{H}-\mathrm{H}$ and L-L pairs counted again; this randomization was repeated 1000 times, to obtain a frequency distribution for the total number of like pairs expected when the observed quadrat counts are located at random. The probability of the actual number of $\mathrm{H}-\mathrm{H}$ or L-L occurring by chance was taken to be the proportion of occasions for which the value in the randomizations was greater or less than for the raw data. This process was applied to three sizes of square blocks, $20 \mathrm{~cm}, 2 \mathrm{~m}$ and $5 \mathrm{~m}$ for the full 1998 data and at $20 \mathrm{~cm}$ and $3 \mathrm{~m}$ for the reduced area mapped in all three years, to examine the grain of the pattern (sensu Dungan et al. 2002) at which any structure is apparent.

We note that the test most often applied to determine randomness in count-per-unit data is to examine whether the variance:mean ratio departs significantly from 1 , the value expected for a Poisson distribution. The value of the ratio is then used as a measure of aggregation (e.g. Southwood 1966). However, this method is often inappropriate for mapped data, due to spatial autocorrelation among quadrats, as well as being flawed logically: the mean can equal the variance even for data that are not Poisson-distributed (Hurlbert 1990; Dale 2000).

\section{What form of spatial structure? (Fig. 1B)}

Given that aggregation is present in the spatial distribution of seedlings, what form does it take? Patterns can be patchy, with a mosaic of high and low densities, and the patches may have the same properties in all directions (isotropic) or they may be elongated in particular

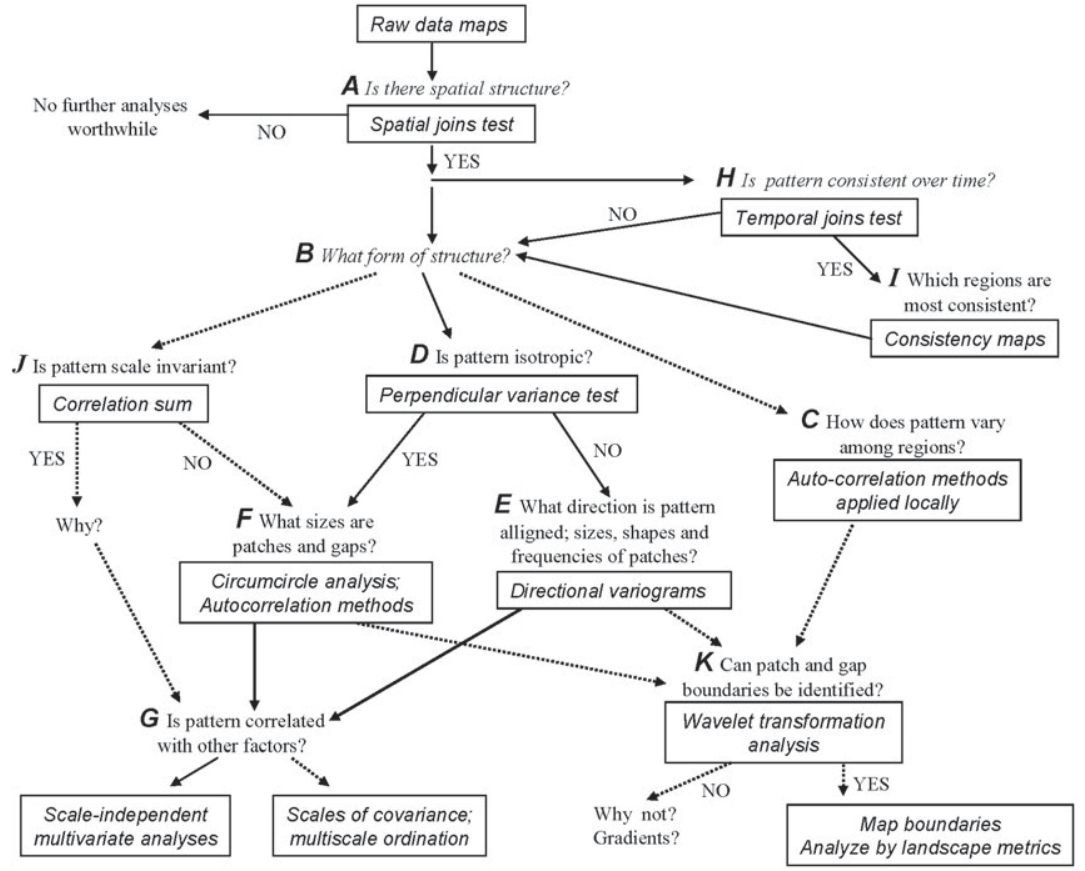

Fig. 1. Schematic representation of the types of decisions made in an 'adaptive analysis' of a spatial data set, as in this paper. Note that not all possible questions are included; some (dotted lines) are examined for this data set in other papers or are the subject of ongoing research. 
directions (anisotropic). Methods for examining a pattern within an area can be 'global', aimed at summarising pattern over the whole area, or 'local', in which variation in pattern within the area is analysed. Most global methods assume second-order stationarity of the data (Legendre \& Legendre 1998) and this may not be strictly true for many weeds: there is often aggregation of weeds in some places, with local high density and variance, and other regions in which weeds are entirely absent and variance is locally zero. However, there seems to be little agreement over how to test statistically whether departures from stationarity are sufficient for a global method to be invalid. It is usual, instead, to decide which approach appears to be justified by visual examination of maps. For example, although there is spatial variation in the density of $A$. calendula, this variation appears to consist of smooth transitions of density throughout the area and with no obvious regions in which variance between neighbouring quadrats is likely to be particularly greater than in others. Global analyses are therefore likely to be applicable to this species. If data are clearly non-stationary, local versions of global analyses can be adopted, in which the particular method is applied to local subsets of the data sequentially across the area and the resulting statistic is then mapped (Fig. 1C). For O. pes-caprae, which is clearly non-stationary, there was little point in local analyses, since the species is confined to a single part of the field: the pattern is obvious and its attributes can be described verbally.

\section{Is pattern isotropic? (Fig. 1D)}

Three of the four species in 1998 appear to have elongated patches or striations of high density in a north-south direction. There was also some suggestion of striations in an east-west direction, but this could be related to recorder bias (since data were collected from transects in that direction). Is this apparent anisotropy real? We were fortunate that our mapping grid was aligned with the direction of the striations: this enabled us to use a very simple test for the presence of anisotropy. We divided the area into $20 \mathrm{~cm}$ by $5 \mathrm{~m}$ blocks in the north-south direction, and then repeated this in an eastwest direction. The length of these blocks was chosen to be the same size as the frame of quadrats, thus spanning the five observers in the north-south direction and ensuring that the test would not reflect observer bias. If these long, thin quadrats are aligned with striations, then they will have greater variance in mean density than if they are at right angles to the striations. The ratio of the variances in the two directions $\left(V_{N S} / V_{E W}\right)$ is thus related to the degree of anisotropy. This test has no name, but we will refer to it as a 'perpendicular variance ratio'. To establish the frequency distribution of $V_{N S} / V_{E W}$ for a random distribution, we re-randomized the raw data 1000 times, as for the 'joins' test. The reader should note that this is an easy test to conduct and is in the tradition of quadrat analysis.

Sizes, shapes and frequencies of patches (Fig. 1E)

Given that there is pattern and that there is anisotropy running $\mathrm{N}-\mathrm{S}$, can we characterise this numerically? Is there a definable size, in N-S and E-W directions, of higher density and lower density regions? How does this vary between years? Autocorrelation and autocovariance methods are appropriate to such questions. For A.calendula the stationarity requirement is very nearly met when the raw data are aggregated into quadrats of at least $60 \mathrm{~cm} \times 60 \mathrm{~cm}$ (Cousens et al. 2002).

We used the S-Plus Spatial Statistics 1.5 (Insight$\mathrm{ful}^{\mathrm{TM}}$ ) module to generate graphs of autocorrelation coefficients, calculated for increasing distances apart (the lag distance), in N-S and $\mathrm{E}-\mathrm{W}$ directions for $A$. calendula (Kaluzny et al. 1998; Legendre \& Legendre 1998). These 'correlograms' indicate the degree of autocorrelation, which takes values between 1 and -1 . Specifically, the autocorrelation coefficient $\left(\rho_{h}\right)$ is calculated as a ratio of covariances:

$\rho_{h}=C_{h} / C_{0}=1-\gamma_{h} / C_{0}$

where $C_{h}$ is the covariance of pairs of points separated by distances $h, C_{0}$ is the finite variance of the random field, and $\gamma_{h}$ is the corresponding semivariance (Kaluzny et al. 1998). Semivariance is a measure of spatial structure that comes from geostatistics. It is familiar to many ecologists and conveys much of the same information as other commonly used methods such as Geary's $c$ and Morin's I (Dale et al. 2002). The 'range', a measure of the average distance between the centres of adjacent high and low density areas, is often estimated by fitting an appropriate function to the semivariance (Webster \& Oliver 2001). The range is the distance at which the semivariance reaches a constant upper limit. In most of our data, mathematical functions with acceptable goodness of fit could not be found, hence informal estimates of key attributes of the variograms are presented. 'Fields of view' for the analyses were set to $10^{\circ}$ about each direction. The location of each observation (the local density) was assumed to be at the midpoint of each quadrat.

\section{What sizes are patches and gaps? (Fig. $1 F$ )}

When there is recruitment, short-range dispersal will result in aggregation around the parent plants (Green 1994; Shaw 1995). For annual weeds, seeds may land within a few tens of centimetres of their parents. Cultivation and other farming operations tend to blur the 
effects of such 'seed shadows' prior to emergence from the seed bank (Cousens \& Mortimer 1995), but this effect can be very limited, again to a few tens of centimetres, even over two years (Howard et al. 1991; Rew \& Cussans 1997; Brain \& Marshall 1999; Mead et al. 2003). Another cause of clustering of plants is localised edaphic variation, leading to patchiness in environmental parameters relevant to seed germination or seedling survival. Can we detect fine-grained aggregation that would indicate the existence of such mechanisms? Where one plant occurs, do we find many? We examined the data to see whether there was autocorrelation between counts within $20-\mathrm{cm}$ quadrats in 2000; this was restricted to a neighbourhood of eight cells in each direction. The year 2000 was chosen as it followed a year in pasture, when recruitment would have been most likely, and because the density was greatest. Data were restricted to an area of $51 \times 121$ quadrats within which both A. calendula and $E$. botrys patterns were approximately stationary and isotropic (see area indicated on $E$. botrys map in App. 2b). Density in the other two years was insufficient to detect clustering at this grain size.

To examine the effect of varying the neighbourhood size, a radial autocovariance function can be defined (Purves \& Law 2002). Writing $p_{i}(x)$ as the number of individuals of species $i$ in quadrat $x$ with Cartesian coordinates $\left(x_{1}, x_{2}\right)$, and $p_{i}(x+\xi)$ as the number in cell $x+\xi$ with Cartesian coordinates $\left(x_{1}+\xi_{1}, x_{2}+\xi_{2}\right)$, the covariance with radial displacement $r$ is defined as

$C_{i i}(r)=\frac{1}{\left|S_{r}\right|} \sum p_{i}(x) \cdot p_{i}(x+\xi)$

where $S_{r}=\{(x, x+\xi): r \leq|\xi|<r+\delta r\}$ and $|\xi|=\sqrt{\xi_{1}^{2}+\xi_{2}^{2}}$.

$S_{r}$ is therefore the set of all pairs of quadrats separated by a radial distance of between $r$ and $r+\delta r, \delta r$ being here $0.2 \mathrm{~m}$, the linear unit of a single quadrat. $\left|S_{r}\right|$ is the number of cell pairs in the set $S_{r}$. This measure is made dimensionless by dividing by the expected value $E\left[C_{i i}(r)\right]$ under complete spatial randomness (see Purves \& Law 2002). A value of this statistic close to unity implies that the spatial pattern of $i$ is close to random at distance $r$; a value greater than one implies aggregation; a value less than one implies over-dispersion. The statistic is closely related to Moran's $I$ and Geary's $C$, but is not a central moment; it describes how population density at distance $r$ is perceived by a plant on the average (relative to the mean density). Numbers within quadrats were randomized and the covariance calculated again; this was repeated 1000 times to calculate a $99 \%$ confidence 'envelope' for the results.

Since we have two congeneric species present in the field, it is relevant to ask whether they have similar niches, or whether they tend to occupy different parts of the field? The patterns themselves appear to differ in the $45 \mathrm{~m} \times 75 \mathrm{~m}$ area, with $E$. cicutarium being more abundant to the southwest while $E$. botrys is most abundant in the southeast and in an E-W band across the middle (App. 2). But at a fine scale, is there any evidence that they tend not to co-occur? To examine this, we calculated the spatial cross-covariance according to the method of Purves \& Law (2002). We calculated 99\% significance envelopes from 1000 random so-called 'toroidal shifts' of the data (Upton \& Fingleton 1985). A toroidal shift serves to maintain the spatial correlation structure of the data while randomizing its position.

Close visual inspection of some of the maps suggested that there may be 'holes' in parts of the E. botrys pattern, surrounded by 'strings' of quadrats containing plants. To test to see whether the holes are a repeated phenomenon across the pattern with a consistent size, rather than simply a chance occurrence or a deceit of the eye, we used a modification of the circumcircle method of Dale \& Powell (2001) for use with lattice data (similar to cluster detection methods, see Fotheringham \& Zhan 1996). Rather than evaluating the number of plants in circumcircles of various scales defined by the locations of individual plants measured as points (as in the original method), we evaluated counts of plants in quadrats whose midpoints lay within circles of varying scale located on a regular grid across the data set. The scales of gaps and patches in the data were determined by calculating variances at various scales for circles with high (patches) and low (gaps) plant density at each scale, while the overall scale of pattern in the data was determined by calculating variances for all circles at each scale. We analysed $20 \mathrm{~cm}$ quadrats in the same 51 $\times 121$ quadrat area as for the previous test.

\section{Is pattern correlated with other factors? (Fig. $1 G$ )}

In many circumstances, particularly when the study area extends to several hundreds of metres, soil parameters contribute significantly to spatial pattern in plants. The presence of other species may also affect distributions through competition or allelopathy. Having demonstrated that there is spatial structure within our species data, it is of interest to know how much of that structure is correlated with other abiotic and biotic variables.

In September 2003, the apparent soil electrical conductivity $\left(E C_{a}\right)$ across the 0.9 ha area was surveyed using an EM38-DD (dual dipole ground conductivity meter) towed along on a sled by a four-wheeled motorcycle. This assessment coincided with a time when there was a well-developed, weedy pasture. Data were collected automatically from two depths, ca. $0.8 \mathrm{~m}$ in the horizontal dipole $\left(E C_{a} h\right)$ and ca. $1.5 \mathrm{~m}$ in the vertical dipole $\left(E C_{a} v\right)($ McNeill 1992), with readings taken at 
horizontal intervals at about $1 \mathrm{~m}$ spacing. Each record was located using a Differential Global Positioning System (DGPS) receiver. Height above sea level was also recorded at 1-s intervals using a Trimble ${ }^{\mathrm{TM}}$ realtime kinematic GPS, thus allowing the construction of a digital terrain model.

The EM38 survey data were used to construct a sitedirected sampling scheme that accounted for the $E C_{a}$ variation observed at both depths. Twenty soil cores were extracted across the site and geo-referenced using a DGPS receiver. The depth of the topsoil (A horizon) and the deepest roots were measured on the cores immediately after extraction. Samples of soil were taken from the A horizon (0-30 cm approx) and B horizon (50-70 $\mathrm{cm}$ ) and analysed for particle size analysis (\% gravel, sand, silt and clay), gravimetric moisture content (w), $\mathrm{pH}$ (in water and in $\mathrm{CaCl}_{2}$ ) and $E C_{e}$. The limited number of cores was due to cost; it was hoped that the soil core information could be regressed against the $E C_{a}$ and elevation data to provide predictions of soil properties across the survey area. This was not the case, with poor model fits $(r<0.7)$ for the majority of soil properties (results not shown). The analysis of the impact of the local environment was therefore restricted to the $E C_{a}$ and primary digital terrain attributes.

Since we were unable to conduct a detailed weed seedling survey in the same year as the soil survey, a coarser vegetation survey was conducted on 25.06.2003. The percentage cover of each species and bare ground were estimated visually in $0.25-\mathrm{m}^{2}$ quadrats on a grid of approximately $5 \mathrm{~m} \times 10 \mathrm{~m}$. The locations of these 203 points were recorded by differential GPS to an accuracy of approximately $20 \mathrm{~cm}$. Weed cover was interpolated on to the 20 soil core points and to the $60 \mathrm{~cm}$ quadrat grid using punctual kriging with a global variogram.

EM38 and elevation data were interpolated to the soil core locations and to the $60 \mathrm{~cm}$ grid of quadrats using block kriging (using a $5 \mathrm{~m} \times 5 \mathrm{~m}$ block size) with a local exponential variogram structure. Two primary digital terrain attributes, aspect and slope, were derived from the interpolated elevation data, on the $60-\mathrm{cm}$ grid of the entire area, in ARC/INFO (ESRI ${ }^{\mathrm{TM}}$ ArcGIS $^{\mathrm{TM}}$ ). As the area is small and topographic information outside its boundary was not available, other primary and secondary digital terrain attributes were not considered. This was because boundary effects would have led to little or misleading information. When required, the values for slope and aspect were extracted directly from the ARC/ INFO grid files. Aspect was also converted into a score from 1 to 4 based on northerly aspect $(\mathrm{NW}-\mathrm{NE}=1, \mathrm{~W}$ $\mathrm{NW}$ and $\mathrm{E}-\mathrm{NE}=2, \mathrm{~W}-\mathrm{SW}$ and $\mathrm{E}-\mathrm{SE}=3, \mathrm{SE}-\mathrm{SW}=4)$.

The weed counts in $60-\mathrm{cm}$ quadrats that included the soil cores were extracted from the 1998 data set, as well as the mean density in a grid of nine quadrats centred on each soil core. This was done to allow for the error associated with GPS location and to reduce noise in the weed counts. It is unlikely that the soil properties measured would vary considerably over an area of $3.24 \mathrm{~m} 2$. In 2000 and 2002, with the reduction in the area surveyed, only counts for eight soil cores were available and these data were therefore not analysed.

The data extraction process thus resulted in two data tables: one with Cartesian coordinates of the 20 soil samples, soil data for the topsoil and subsoil, weed seedling counts in 1998, weed cover in 2003, $E C_{a} h$ and $E C_{a} v$, elevation, aspect and slope; the other with Cartesian coordinates for each 60 -cm quadrat, weed seedling counts in 1998, 2000 and 2002 (if recorded), weed cover in 2003, $E C_{a} v, E C_{a} h$, elevation, aspect and slope.

A correlation matrix was derived in JMP ${ }^{\mathrm{TM}} 5$ (SAS Institute Inc.) between all soil and environmental variables (except $\mathrm{pH}$ in 1:5 water) and seedling counts in 1998 for the 20 soil sampling points. Similarly, a correlation matrix between $E C_{a} h, E C_{a} v$, elevation, slope, weed seedling counts (all three years) and weed cover in 2003 was derived for the quadrat grid data. Regression tree analysis in $S$-Plus was used to identify the dominant soil and environmental variables that contributed to variation in seedling emergence and weed cover, using the same variables as in the correlation matrices (Wiles $\&$ Brodahl 2004). For each analysis the minimum node size was set at $15 \%$ of sample size and the minimum node deviance at 0.1 . This limited the branching in the regression tree so that dominant effects could be identified.

\section{Is pattern consistent over time? (Fig. $1 \mathrm{H}$ )}

It can be seen from the maps that some patterns, as well as overall abundance, clearly vary over time. Rather than rely on visual interpretation, we need to quantify the inconsistency and to determine the extent to which the variation occurred at random. To examine the consistency of pattern across time, we examined the density of seedlings in each quadrat and compared it with the year's median. Counts were made of the number of quadrats that either had lower or higher densities than the median in all three years. Quadrats were either $20 \mathrm{~cm} \times 20 \mathrm{~cm}$ or $3 \mathrm{~m} \times 3 \mathrm{~m}$, so that we could examine whether the spatial dynamics was consistent across scales. We then conducted a toroidal shift of the data grid by random north and west distances for each year and repeated the calculations. This was done $1000 \times$ in order to obtain a probability that the number of consistent quadrats was random. The test is basically a joins test using temporal rather than spatial neighbours.

Spatial variation in the consistency of regions (Fig. 1I) can be shown by maps with symbols for quadrats that have a given frequency of either high or low abundance over time (see also Wilson \& Brain 1991). 


\section{Further questions}

For completeness, Fig. 1 indicates further aspects of the data that can be explored. Some of these have been presented elsewhere: explorations of scale-invariance and fractal dimensions (Fig. $1 \mathrm{~J}$ are presented in Cousens et al. 2004). We did not pursue the question of boundary detection (Fig. 1K), but we would be happy to provide the data to other researchers to follow up on this aspect. Kriging has been used to produce contour maps of $A$. calendula distribution (Cousens et al. 2002).

\section{Results}

\section{Is there spatial structure?}

Grey-scale maps for the 20-cm quadrats of the 1998 data are given in App. 1, and for the reduced 1998-2002 data in App. 2 and Fig. 2. For the $90 \mathrm{~m} \times 100 \mathrm{~m} 1998$ data set, the number of $\mathrm{H}-\mathrm{H}$ and $\mathrm{L}-\mathrm{L}$ pairs is greater than for any of the randomizations (i.e. $p<0.001$ ) for all species and for all quadrat sizes. The one exception is the number of L-L pairs for 5-m quadrats of $B$. arvense, for which $p=0.23$. For the $45 \mathrm{~m} \times 75 \mathrm{~m}$ area mapped in all three years, the number of $\mathrm{H}-\mathrm{H}$ and $\mathrm{L}-\mathrm{L}$ pairs is again greater than any of the randomizations (i.e. $p<0.001$ ), with a few exceptions mostly at the 3-m grain size. Counts in $3 \mathrm{~m}$ quadrats for $E$. cicutarium $(\mathrm{H}-\mathrm{H} p=$ 0.002 ; L-L $p=0.005$ ) and $E$. botrys (L-L $p=0.003$ ) in 2002 are also significantly non-random. However, counts in 3-m quadrats of B. arvense in 1998 (L-L $p=0.46$ ) and 2002 (L-L $p=0.22$ ) and of $E$. botrys in 2002 in $20-\mathrm{cm}$ quadrats ( $\mathrm{H}-\mathrm{H} p=1.0$; L-L $p=0.41$ ) do not depart significantly from randomness. All the exceptions were for species/year combinations in which mean densities are very low. The overall conclusion is therefore that there is aggregation within the data for almost all species/ years and for all quadrat sizes studied.

\section{Which form of spatial structure?}

Table 1 gives the values of $\mathrm{V}_{\mathrm{NS}} / \mathrm{V}_{\mathrm{EW}}$ for the full 1998 data set and the reduced data for all three years. $A$. calendula and $O$.pes-caprae have significant anisotropy at this scale in all years. B. arvense is anisotropic in the first year in the full area, for which there are sufficient data. Of the two Erodium spp., only E. cicutarium showed significant anisotropy, in 2000.

Since the steps in the investigation of spatial structure differ among the species, further results will be presented separately for each weed:

A. calendula. Mean density of this species was $11 / \mathrm{m}^{2}$ in the entire area in 1998, while in the area common to all three years the density was $12 / \mathrm{m}^{2}$ in $1998,15 / \mathrm{m}^{2}$ in 2000 and only $1.2 / \mathrm{m}^{2}$ in 2002 . There are apparent pairs of lines of higher density in the maps, running (northsouth) at roughly 20-m intervals; in the most distinct case, the pair of lines is $1.8 \mathrm{~m}$ apart. Other areas of higher or lower density give the overall pattern a blotchy appearance, but no patches separated by gaps of zero density are obvious.

The correlogram for the N-S direction for the full 1998 data set is smoother than for E-W, flattening after a lag distance of about 10 to $20 \mathrm{~m}$ (Fig. 3a). The E-W variogram has three peaks, at 18,36 and $54 \mathrm{~m}$. Together, these graphs indicate elongated areas of high or low density, about 10 to $20 \mathrm{~m}$ in length (in the N-S direction) and recurring at $18-\mathrm{m}$ intervals from east to west.

In all three years, the autocorrelation coefficient $\left(r_{h}\right)$ is greater over short distances (up to about $10 \mathrm{~m}$ ) for the $\mathrm{E}-\mathrm{W}$ direction, becoming greater for the N-S direction at large distances (Fig. 3b). The periodicity in the E-W direction is most marked in 2000, but in this year (and in this part of the area) the peaks are about $7 \mathrm{~m}$ apart. The difference between $\mathrm{N}-\mathrm{S}$ and $\mathrm{E}-\mathrm{W}$ beyond a lag distance of $20 \mathrm{~m}$ is also greatest in 2000, indicating a greater degree of anisotropy. Anisotropy is least for this smaller area in 1998. This is apparent in App. 2.

Results for local spatial covariance analysis (limited to a $2-\mathrm{m}$ radius) within the $10.2 \mathrm{~m} \times 24.2 \mathrm{~m}$ rectangle are shown in Fig. 4a. There is significant autocorrelation among quadrats up to about four quadrats away: there is, therefore, evidence of localised aggregation of plants. The spatial covariance function approaches a value of 1 as distance increases, indicating stationarity, and there is little evidence of anisotropy over these short distances.

Table 1. Ratio of the variances of $20 \mathrm{~cm} \times 5 \mathrm{~m}$ quadrats aligned north-south and east-west $\left(\mathrm{V}_{\mathrm{NS}} / \mathrm{V}_{\mathrm{EW}}\right)$. Values greater than 1 indicate anisotropy in the north-south direction. Significance values, shown in parentheses, refer to the probability of achieving a value as high as this by chance: $* * *=p<0.001$.

\begin{tabular}{|c|c|c|c|c|c|}
\hline & A. calendula & E. botrys & E. cicutarium & O.pes-caprae & B. arvense \\
\hline $90 \mathrm{~m} \times 100 \mathrm{~m}$ data set 1998 & $1.33(* * *)$ & $1.03(p=0.11)$ & - & $1.99(* * *)$ & $1.78(* * *)$ \\
\hline $45 \mathrm{~m} \times 75 \mathrm{~m}$ data set 1998 & $1.33(* * *)$ & $1.04(p=0.06)$ & - & $1.66(* * *)$ & $1.29(* * *)$ \\
\hline $45 \mathrm{~m} \times 75 \mathrm{~m}$ data set 2002 & $1.05(p=0.04)$ & $1.00(p=0.72)$ & $1.00(p=1.0)$ & $1.36(* * *)$ & $1.00(p=1.0)$ \\
\hline
\end{tabular}




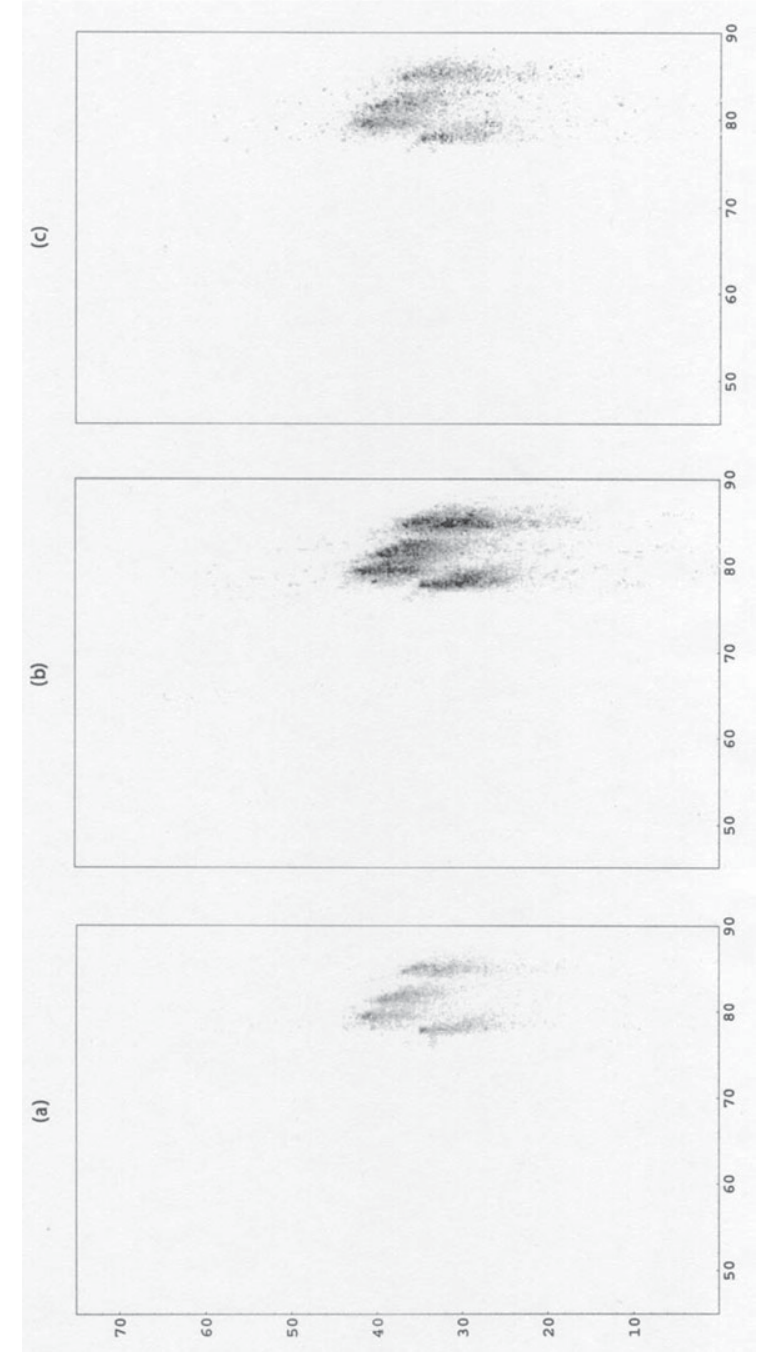

Fig. 2. Grey-scale distribution maps of Oxalis pes-caprae in the $45 \mathrm{~m} \times 75 \mathrm{~m}$ sub-area in 1998, 2000 and 2002. A black square represents the greatest number of plants of that species in a $20 \mathrm{~cm} \times 20 \mathrm{~cm}$ quadrat in any of the three years; absence is shown as white. Note that South is at the top of all maps.

Erodium botrys. This species had very low abundance in all years, averaging only 0.53 plants $/ \mathrm{m}^{2}$ in 1998 in the whole area, compared with $0.16 / \mathrm{m}^{2}$ in $1998,0.55 / \mathrm{m}^{2}$ in 2000 and $0.02 / \mathrm{m}^{2}$ in 2002 in the area in common between years. In the maps, it is distinctly more abundant on the eastern side, and along a band across the centre of the 1998-2002 area. There is no visible anisotropy and the test for anisotropy is non-significant (Table 1).

For the circumcircle analysis, there is a peak in the variance for gaps at $0.8 \mathrm{~m}$ and a plateau above $1.4 \mathrm{~m}$ (Fig. 5). For patches, there is a strong peak at $0.2 \mathrm{~m}$, as well as at $1 \mathrm{~m}$ and $2 \mathrm{~m}$. Peaks are often seen with circumcircle methods at the smallest spatial resolution and may be artefacts rather than indicative of strong

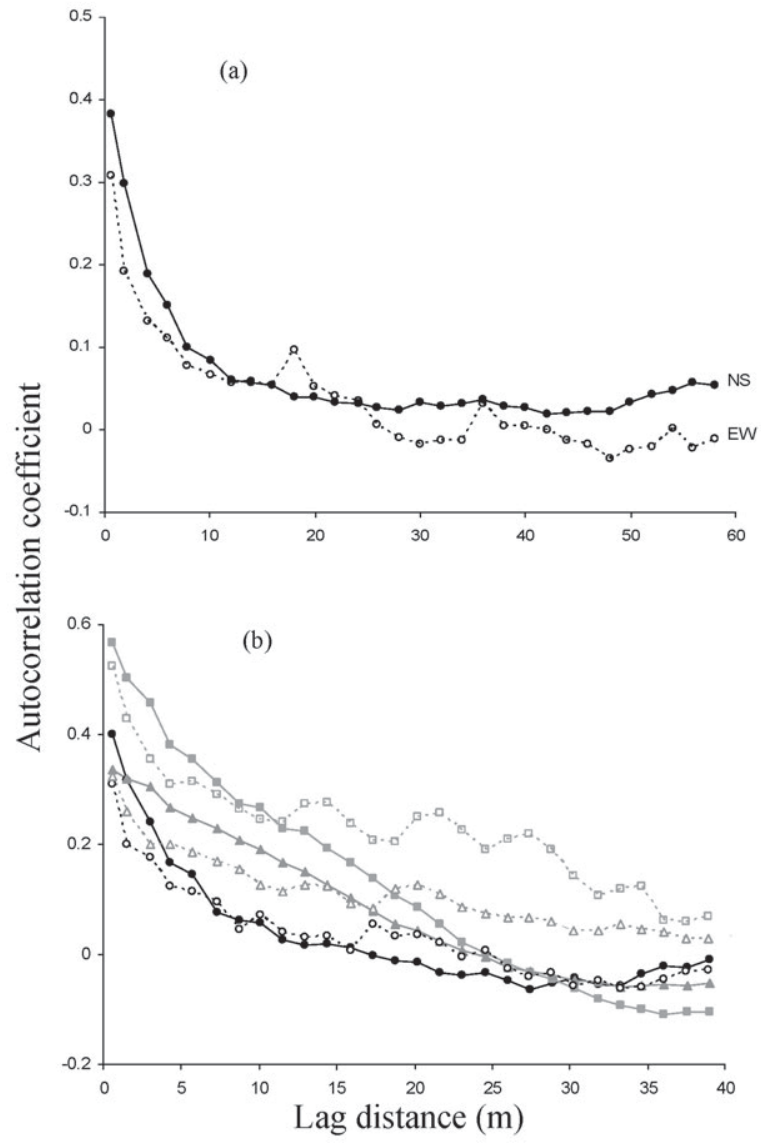

Fig. 3. Directional correlograms for Arctotheca calendula (a) $90 \mathrm{~m} \times 100 \mathrm{~m}$ area in 1998, and (b) $45 \mathrm{~m} \times 75 \mathrm{~m}$ area common to $1998(\bullet), 2000(\boldsymbol{\square})$ and $2002(\boldsymbol{\Delta})$. Closed symbols refer to the $\mathrm{N}-\mathrm{S}$ direction, open symbols to E-W.

patterns. Unfortunately, the current implementation of this method does not allow the statistical significance of the variance peaks to be determined. The holes also appear to be smaller on the eastern side of the area, where the weed is more abundant. There is no significant autocorrelation within the $10.2 \mathrm{~m} \times 24.2 \mathrm{~m}$ rectangle (Fig. 4b). The spatial covariance function approaches a value of 1 as distance increases, indicating stationarity, and there is little evidence of anisotropy over these short distances.

Erodium cicutarium. This species was absent in 1998, reached about half the abundance of E. botrys in 2000, and then there were only four seedlings seen in 2002 . Analysis of pattern must therefore be confined to 2000 . Other than that there is significant aggregation and anisotropy (running in the N-S direction), it is difficult to extract further information about the pattern owing to the sparseness of the data. There is no evidence of spatial cross-correlation (results not shown): the species 


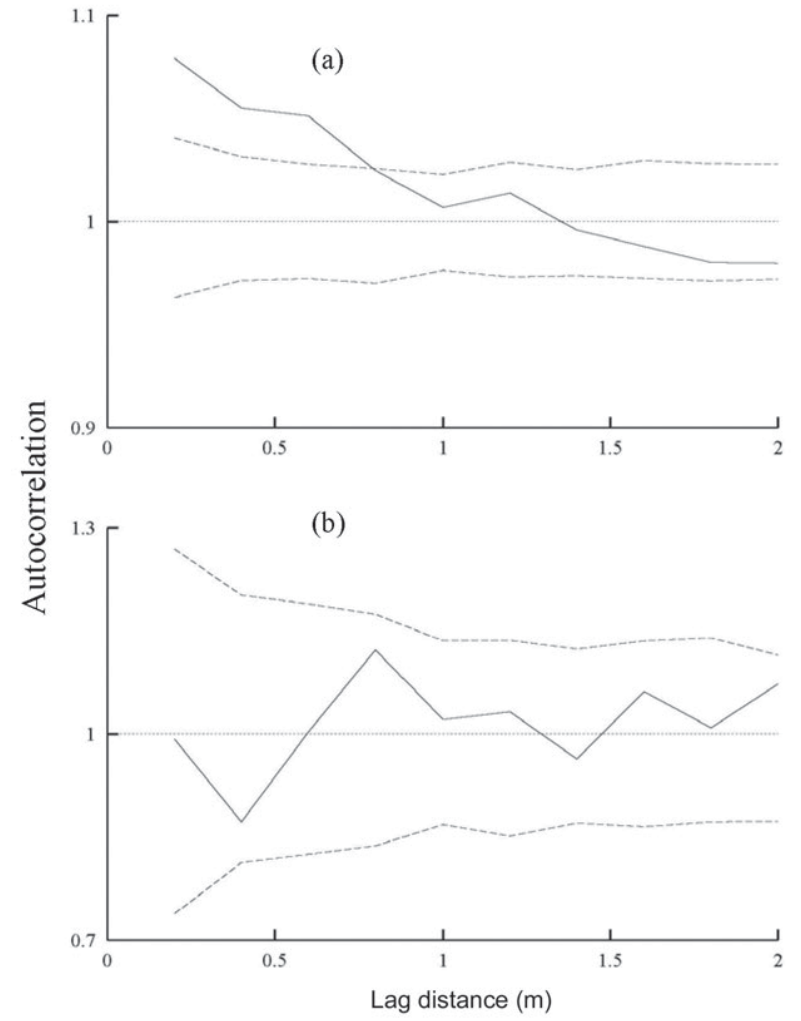

Fig. 4. Localized autocorrelation analysis of spatial pattern in 2000 for (a) Arctotheca calendula and (b) Erodium botrys, assuming an isotropic pattern. Analysis was restricted to the $10.2 \mathrm{~m} \times 24.2 \mathrm{~m}$ rectangular area shown in App. 2b. Dashed lines are $99 \%$ confidence intervals.

within this sub-area are therefore independently located (there is also no cross-correlation between A. calendula and either Erodium species).

Oxalis pes-caprae. This species occurred only on the extreme western side of the area and is clearly aggregated. Numbers were 5701 leaf rosettes in 1998, 33474 in 2000 and 11243 in 2002. The pattern is clear and unambiguous: there is little point in using statistics to explore this pattern further. The main concentration of plants consists of four comet-like patches, with the greatest density at their southern end (Fig. 2). The highest densities in the comet heads were over 40 rosettes in a $20 \mathrm{~cm} \times 20 \mathrm{~cm}$ square in 2002 . Their 'tails' tend to be parallel, rather than fan-like; there are also some plants forming outward lines to the south, slightly curving. Given the similar sizes of the four patches, we can speculate that there was an original introduction (or relict population) of four plants from which the pattern spread.

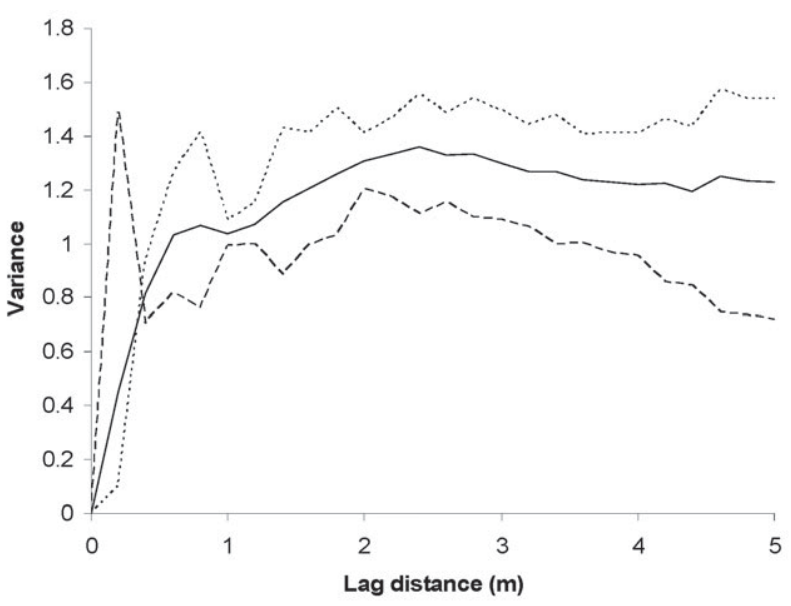

Fig. 5. Modified circumcircle analysis (see text) of Erodium botrys in 2000. Analysis was restricted to the $10.2 \mathrm{~m} \times 24.2 \mathrm{~m}$ rectangular area shown in App. 2. Solid line shows total variance; dashed line shows patch variance; dotted line shows gap variance.

Buglossoides arvensis. This was the least abundant of the species we are describing, with only 111 seedlings in sparse clusters of plants occurring at intervals across the area in 1998 (App. 1). There were no plants in 2000, perhaps because of the different herbicides used in the B. napus crop, and only 26 in the 0.9 -ha area in 2002 . The clusters appear elongated along a N-S axis, again following the direction of most machinery operations. The data do not fulfil the requirements of stationarity for the calculation of a geostatistical range; however, it is not difficult to measure the most dense patches directly. Most patches, regardless of number of individuals within them, occupy an area no larger than $8 \mathrm{~m} \times 2.5 \mathrm{~m}$. Within the main patches, plants are widely spread, but the few quadrats containing multiple plants are towards the centres.

\section{Is pattern correlated to other factors?}

Of the species mapped, only A. calendula and $E$. botrys were widespread and abundant enough within the area to warrant analysis in relation to edaphic factors. For the data set based on the 20 soil core locations, only A. calendula seedling density is significantly correlated with any edaphic measurements. In pairwise correlations there is a negative correlation between seedling count in 1998 and both topsoil $\mathrm{pH}(r=-0.37)$ and maximum root depth $(r=-0.50)$. All other edaphic factors and ancillary variables ( $E C_{a}$ and DTM attributes) have coefficients of determination that are smaller than 10.30l. The cover of A. calendula is more correlated to soil properties than seedling density. However, again the correlations are weak. $E C_{a} v$ and subsoil $E C_{\mathrm{e}}(r=-$ 0.41 and -0.43 respectively) are negatively correlated 


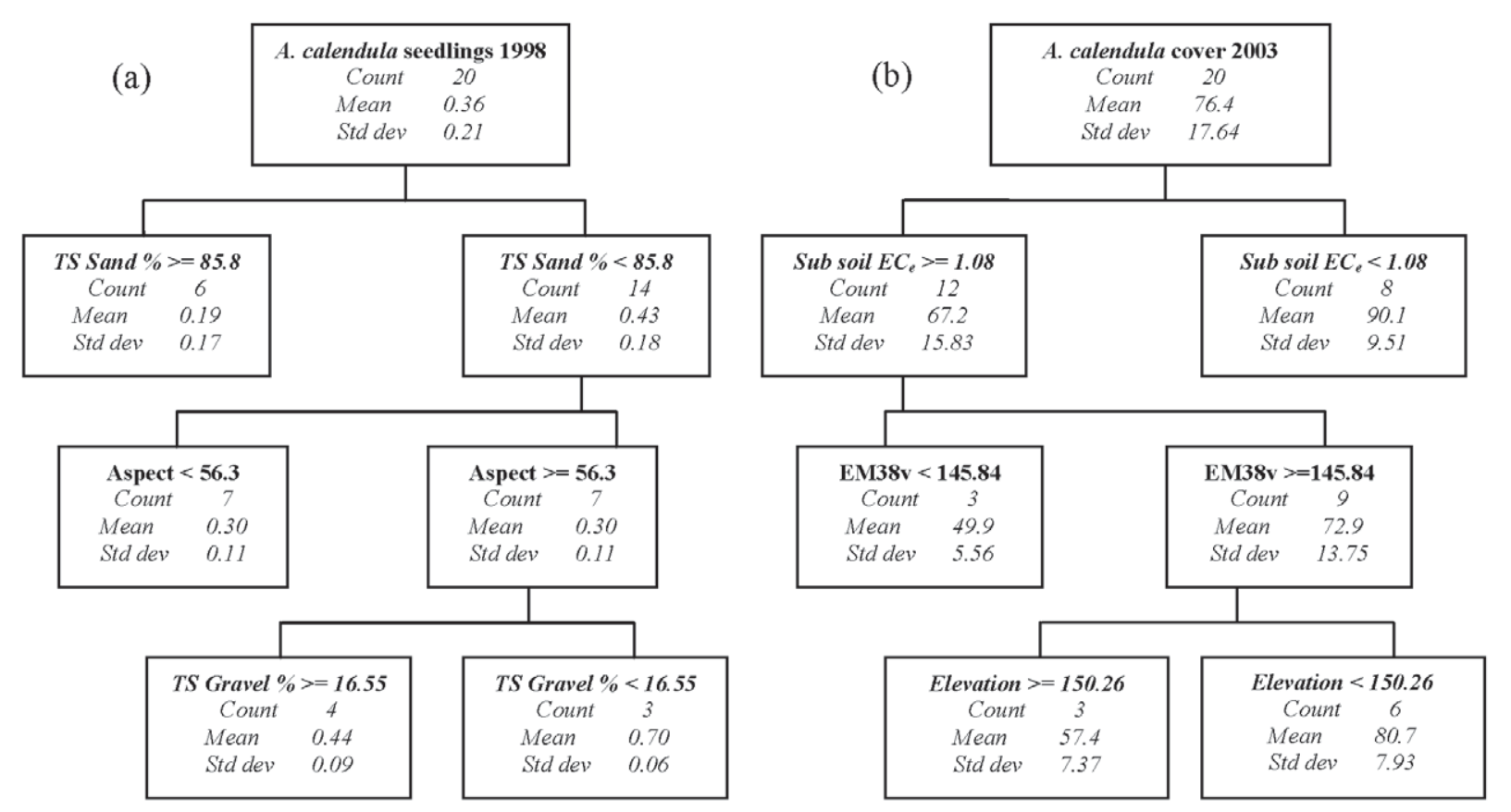

Fig. 6. Regression tree analyses showing soil properties that are related to (a) A. calendula seedling emergence in 1998 and (b) A. calendula cover in 2003.

with $A$. calendula seedling density. There are also negative correlations between $A$. calendula cover and covers of $E$. botrys, L. rigidum and $T$. subterraneum, and a positive correlation between A. calendula cover and cover of broad-leaved species other than E. botrys and $T$. subterraneum. Notably, there is no correlation between A. calendula cover in 2003 and A. calendula seedling density in any year.

Regression tree analysis on the 20 soil core data set (Fig. 6) shows that A. calendula seedling density in 1998 tends to be at greater abundance where \% sand is lower, and within those locations it is at higher densities in NW aspects $(r=0.84)$. The northerly aspect group of points also shows a negative relationship with $\%$ gravel. However, there is no relationship with either $E C_{a}$ reading. In the regression tree of A. calendula cover in 2003 $(r=0.90)$, areas with higher cover are associated with low subsoil $E C_{e}$. For higher $E C_{e}$ values, higher $A$. calendula cover is greater at higher $E C_{a} v$ values and lower elevations.

For the grid of $60 \mathrm{~cm}$ quadrats at locations common to all three years of seedling counts, the results are somewhat different to the 20 soil core locations. A. calendula seedling densities are slightly positively correlated with elevation in 2000 and 2002 and negatively correlated with $E C_{a}$ and terrain attributes in those years. However, there are again no significant correlations between seedling density of $A$. calendula (in any year) and cover of $A$. calendula in 2003. Similarly, the other dominant species in the study area, E. botrys, shows no significant correlation between its cover in 2003 and seedling counts in any year.

Regression tree analysis shows little relationship between seedling densities, $E C_{a}$ values and terrain attributes for all the weed species. For A. calendula, the regression tree model explains only $20 \%$ of variation in the seedling counts. For weed cover, the regression tree analysis produces good predictions, with $r=0.70$ and 0.75 for A. calendula and E. botrys respectively. Areas of high $E C_{a} v$ are associated with higher A. calendula and lower $E$. botrys cover. The output from the regression tree analysis strongly reflects the negative relationship between covers of A. calendula and E. botrys.

\section{Is pattern consistent over time?}

From the previous discussions it is clear that the dynamics of the four species differ. With the exception of $B$. arvense, all species increased in mean abundance from 1998 to 2000, then decreased considerably in 2002. The dynamics of pattern also varied conspicuously among the species.

For A. calendula, the thin striations of higher density in 1998 are not seen in later maps. The autocorrelation coefficients (Fig. 3) show how anisotropy and distances between high and low densities vary between years. The contrast between high and low density areas appears to be greater in 2000 than in 1998. By 2002, the low 
density area at the northern end extends well towards the south. Some areas, previously at higher than average densities, are then well below average while other areas maintain their higher or lower densities.

The number of quadrats consistently at high density is greater than would occur by chance $(p=0.037$ for 20 cm quadrats; $p=0.008$ for $3-\mathrm{m}$ quadrats). The same is true for consistently low density 3-m quadrats ( $p=$ 0.013 ), but not quite significant for $20-\mathrm{cm}$ quadrats ( $p=$ 0.064 ). The locations of consistently high and low $3 \mathrm{~m}$ quadrats are shown in Fig. 7. The most northern part of the area (bottom of the map) tends to be at lower than median density every year, while a region to the southwest tends to remain at higher than median density. This is not, however, to say that the most dense areas are always the most dense: clearly, comparing 1998 and 2000 (App. 2), the highest density patches differ in the two years.

The patterns for E. botrys in 1998 and 2000 (App. 2) are clearly very similar; the pairs test for quadrats higher or lower than the median in both years is significant for both 20-cm and 3-m quadrats (for both high and low density, $p=0.005$ for 3 -m quadrats, $p=0.034$ for 20

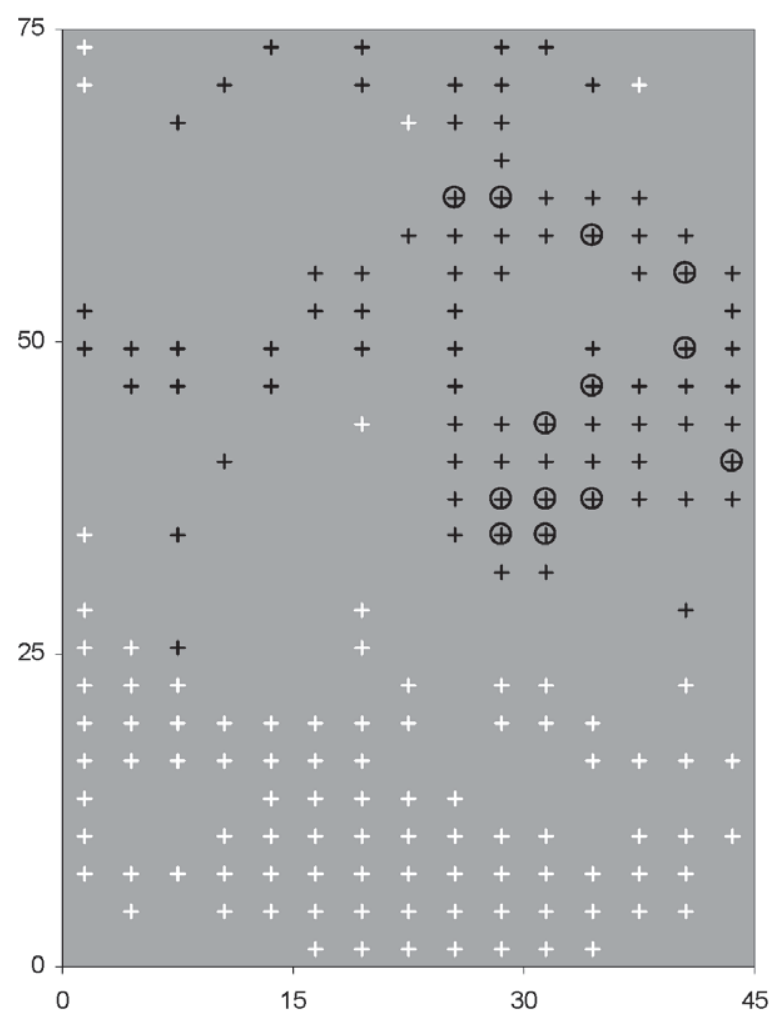

Fig. 7. Locations of $3 \mathrm{~m} \times 3 \mathrm{~m}$ quadrats where the density of Arctotheca calendula in the $45 \mathrm{~m} \times 75 \mathrm{~m}$ sub-area was above the median (black cross), above the 75 th percentile (black circle), or below the median (white cross) in all three years. Symbols are smaller than the size of the quadrat. Note that South is at the top. $\mathrm{cm})$. There were too few plants in 2002 to be able to make definitive statements about consistency across all three years. Although very few $B$. arvense plants were in the area mapped in 2002, a single patch was found outside (but within the area originally mapped in 1998); its location did not coincide with any of the previous patches. Plants in this patch were widely spaced, with no indication of higher densities towards the centre.

The main patches of $O$.pes-caprae, in contrast, were very stable in their position within the field. Although at first sight the maps appear to show that the patches are spreading outwards, the increase in abundance arose mostly from in-filling within the area already occupied. The positions of the tips of the comet heads, the widths of the comet bodies and tails, and the locations of the plants furthest north and south remained the same. Along with mean density, the occupancy of $20 \mathrm{~cm}$ quadrats increased after 1998, from 1961 quadrats in 1998, to 4557 quadrats in 2000, but decreasing to 2785 in 2002. In 1998 there were a few individual plants well away from the main patches, on the eastern side. Even though the population increased almost sixfold from 1998 to 2000 , none of these plants formed new patches: instead, they disappeared. The same was true for outlying plants in 2000, which again failed to establish new patches.

\section{Discussion}

Despite repeated annual disturbances by cultivation, harvesting and other natural and anthropogenic mechanisms, clear spatial structure was apparent over a range of spatial resolutions in this 0.9 ha area. All of the species mapped in this study showed very different patterns, and very different dynamics of that pattern. With the exception of $E$. botrys, which appeared to be out-competed by $A$. calendula in certain parts of the field (see below), these species are behaving independently, not as a community of interacting species. Consideration of the causes of spatial behaviour must, therefore, be on a case-by-case basis.

There was gradual variation in abundance of $A$. calendula, resulting in dense and sparse areas; there were also striations running in a north-south direction, though at different spacings in each year. Patches of $B$. arvense and $O$. pes-caprae were also elongated in a N-S direction. E. botrys was more abundant on one side of the area, while both $O$. pes-caprae and B. arvensis were in very localised patches. Patches, gaps and strings of quadrats containing $E$. botrys were found. A plausible mechanism for the generation of such strings and holes would be the trails along which sheep habitually walk: the crop stubble, as well as the pasture years, are grazed annually by sheep. Although the tracks themselves are 
unlikely to be the same from year to year, their former positions may be revealed if they have acted as preferential sites for dispersal and/or recruitment. The density of O.pes-caprae was greatest in the centre of its patches, perhaps suggestive of an actively spreading population (as predicted by the various reaction-diffusion and integro-difference models, e.g. Skellam 1951; Shigesada \& Kawasaki 1997; Woolcock \& Cousens 2000; Neubert \& Caswell 2000), and elongated, with each patch resembling a comet with tail. Patches of $B$. arvensis, however, were much less concentrated and may indicate the remnants of a past, more abundant population rather than active centres of recruitment: $B$. arvense has certainly declined in recent years as use of trifluralin has increased. Alternatively, perhaps the species has always been uncommon in the field and there are just a few microsites in which it can persist (the species is more typical of heavier soils than at this site: I. Glasgow pers. comm.)

In most cases, it was not possible to ascribe particular processes responsible for the pattern. Cultivation, crop harvest, sheep grazing, ants and other factors are known to move weed seeds around within agricultural fields (Cousens \& Mortimer, 1995), but most of them also cause aggregation. Movement due to cultivation is very limited for the majority of seeds (e.g. Rew \& Cussans, 1997). Mortality due to burning, herbicides and cultivation is also likely to be spatially variable and to result in localised patches. There was anisotropy in all species mapped apart from E. botrys. The direction of the pattern reflected the direction taken for cultivators, spray booms and harvesters, suggesting mechanical influences, but since these all travelled in the same direction (a tree just to the west side of the area forces machinery to travel N-S or S-N) it is not possible to attribute the pattern to particular machinery. The exception was for A. calendula in 1998, where thin striations of greater abundance coincided precisely with tractor tyres from the spraying operation. Perhaps in this case, where rainfall was poor and the soil is sandy, emergence was greater where water accumulated. However, it is acknowledged that not all possible causes of pattern were mapped in every year, and some (such as the tracks of harvesters) were not mapped at all.

Two examples of apparently paradoxical spatial behaviour concern $O$. pes-caprae. Firstly, cross-sections of density through the $O$.pes-caprae patches are suggestive of active expansion, with high densities in the centre declining to the periphery. The shape and direction of patches, along with anisotropy in other species, suggest the strong influence of cultivation in pattern generation. Indeed, since $O$. pes-caprae lacks seeds, dispersal will be entirely at and below ground-level. However, with cultivation still occurring, there appears to be little fur- ther spread during the course of this study other than what might be achieved by vegetative growth from adjacent quadrats. The depth of cultivation has been reduced in recent years (down to $7.5 \mathrm{~cm}$ at most), along with the type of implement: the 'points' on current cultivators and seed drills are narrower than previously. Shallower cultivation may miss many of the $O$. pescaprae propagules, which are often deeper than this (personal observations), while reduced surface area of points will drag fewer of them along.

Secondly, despite conditions being suitable for sizeable population growth between 1998 and 2000, all outlying plants to the east of the main patches failed to initiate new patches. Soil conditions are unlikely to be so unsuitable for $O$. pes-caprae such a short distance away, considering that the crop and other weeds grow well there. Demographic stochasticity is another possibility: the mortality rate may be high and the number of outlying plants is very low. The lack of new patches in that direction, however, indicates that establishment failure has continued over many generations. A possible explanation is that $O$. pes-caprae forms both large and small bulbils, from which rosettes grow the next year. We hypothesize that only the small bulbils could be dispersed along the soil surface by wind or on sheep's feet and hence in a direction perpendicular to cultivation. These small plants must then survive and proliferate within very competitive crops; perhaps, unlike the larger plants in the main patch, they are unable to do so. This could easily be studied through transplanting of large and small bulbils. Perhaps also there is some positive advantage from density-dependence, such as increased allelopathy, resulting in a threshold for establishment - i.e. an Allee effect (Stephens et al. 1999).

One common theme to emerge from the annual species was the poor spatial signal from localised recruitment events. Seedlings tended to be thinly spread. For two of the three sexually-reproducing species, there was no fine-grained autocorrelation that would indicate the existence of seed shadows around the location of parents in previous generations. The absence of seed shadows is unlikely to be because all seeds are dispersed widely throughout the field. Of the five species, only $B$. arvense is known to be taken up by combine harvesters (Moerkerk 2002). Stamp (1989) recorded mean dispersal distances from individual schizocarps of $54 \mathrm{~cm}$ for E. cicutarium and $76 \mathrm{~cm}$ for $E$. botrys under laboratory conditions. Mean distance was concluded to be reduced to less than $30 \mathrm{~cm}$ in the presence of neighbouring plants. Newly-dispersed A. calendula seeds are commonly found clustered in micro-topographic dips within pastures, where they have been washed or blown. Although cultivation moves seeds, this is usually limited in extent, with most remaining close to their original 
positions (Howard et al. 1991; Rew \& Cussans 1997; Brain \& Marshall 1999; Mead et al. 2003). However, sheep are grazed on the field over summer as well as during the pasture phase. They may scatter seeds widely as a result of ingestion, but even then the seeds would be aggregated in faeces.

Perhaps, then, in modern farming systems with effective herbicides and competitive crops, weeds (and particularly those that are primarily pasture species, such as Erodium spp.) may only reproduce in years in which either the appropriate herbicides are not applied or when the field is under pasture. The only years in the sequence studied when this happened were 1999 and 2003. Searches in September 1998 certainly failed to find any mature plants of broad-leaved weeds within the wheat crop. If mortality is high in most years, current agricultural practices may have a profound effect on spatial pattern through the imposition of rare, episodic recruitment and intervening periods with no recruitment. The patterns that we described may arise primarily from annual emergence events from a repeatedly cultivated and long-lived seed bank, but one with zero fecundity (due to $100 \%$ juvenile mortality) in most years. Various evidence suggests that seeds of Erodium spp. may be long-lived (Rice 1985), while dormancy and seed survival over a two-year period varied with population in A. calendula (Dunbabin \& Cocks 1999). Medd (1996) has rightly emphasised the importance of recruitment in the dynamics and management of wild oats populations. Models of weeds and other plants (Wallinga 1995; Murrell \& Law 2003) also show the importance of recruitment in structuring plant populations and communities. However, our results indicate that dormant seed banks may be equally important in the dynamics and structuring of populations during periods where recruitment is minimal. Unfortunately, assessment of variation in seed banks at a resolution comparable with the other measurements in this study was not possible within the resources available.

Although there was variation in weed abundance across the field that did not seem to be related to farming activities, the influence of edaphic factors on seedling density seemed to be weak. EM38 measurements were taken on a fine grid, but only 20 soil cores were taken (because of resource limitations). Hence, either soil variation was not great enough to be responsible for patterns in emergence or the soil sampling intensity was not sufficient. Correlation between soil factors and densities of particular weeds has been reported where soil variation is very marked (e.g. Dieleman et al. 2000). However, in our study, the areas of greatest A.calendula emergence were often not in the same positions as areas of greatest plant biomass (at least as seen in the pasture in 2003). A. calendula biomass per unit area was greater on one side of the field than on the other, perhaps due to a soil fertility gradient that does not affect emergence. This is reflected in the strong negative correlation between A. calendula cover and $E$. botrys cover in the pasture in 2003. A. calendula was clearly the more aggressive of the two species: where they were side by side, A. calendula's leaves curved up and over E. botrys, whereas the latter species kept its rosette leaves close to the ground. Although not significant (perhaps due to low seedling densities), E. botrys emergence in all three years seemed to be greatest where there was least $A$. calendula cover. Unfortunately, in cropping years (such as 1998, 2000 and 2002) crop competition and herbicides reduce weed cover almost to zero, making cover assessment in the years of seedling counts impossible.

It may well be that different edaphic influences act at different stages in the life-cycle, thus superimposing their effects and masking the signal from each process. The regression tree analysis of the soil core data indicates this, with $A$. calendula seedling density being driven by topsoil sand \% and gravel \% and a northerly aspect. At higher sand and gravel \%, emergence was suppressed, indicating that areas of higher silt and clay (i.e. higher potential moisture retention) were preferable for emergence. Emergence also benefited from increased solar radiation interception (northerly aspects). In contrast, A. calendula cover was best explained by subsoil factors $\left(E C_{e}\right.$ and $\left.E C_{a} \mathrm{v}\right)$ and elevation, suggesting that subsoil conditions may drive establishment (not disregarding inter-species competition). This was replicated in the regression tree analysis of the $60 \mathrm{~cm}$ quadrat data, with $A$. calendula cover related to $E C_{a}$ and terrain attributes, but showing little relationship to seedling density.

The very high year $\times$ spatial location $\times$ emergence interactions displayed by seedling densities of two species in this field were perhaps driven, in this mediterranean environment, by water. There is some evidence, namely a slight negative correlation with lower sand and gravel content, that seedling emergence in some years is related to topsoil water-holding capacity. Seedling density of all species decreased considerably from 2000 to 2002 , coinciding with a marked reduction in rainfall. Annual rainfall at the nearest meteorological recording station (Natimuk, $5 \mathrm{~km} \mathrm{NW}$ ) was $384 \mathrm{~mm}, 349 \mathrm{~mm}$ and $256 \mathrm{~mm}$ in 1998, 2000 and 2002, respectively, compared with a long-term average of $440 \mathrm{~mm}$. The early season rainfall (March-June) in 1998 was almost double that in 2000 and $2002(136 \mathrm{~mm}, 75 \mathrm{~mm}$ and $76 \mathrm{~mm}$, respectively, compared with a long-term average of $144 \mathrm{~mm}$ ).

Interpretations of the data in this study were reached from the use of a variety of often quite old methods. Using what we have termed an 'adaptive analysis' approach, these methods were applied in a sequential manner, asking more revealing questions at each step; 
each method was selected according to the questions prompted by the particular pattern. Thus we select the appropriate tool from our spatial toolbox at each stage. We doubt whether we would have achieved the same level of insight from applying one method, or even several, across-the-board to all species, regardless of how 'advanced' the methods are considered. Consider, for example, if we had just applied one of the several published omni-directional autocorrelation methods: we would have failed to capture the anisotropy of the data. There is no shortage of indices, tests and graphical presentations with which ecologists can explore spatial pattern (e.g. Musick \& Grover 1991; Dale 1999). The challenge, however, is to use these in support of scientific deduction so as to gain a better intuitive understanding of the way that species are distributed in space and the processes leading to this pattern. This is best achieved, in our opinion, through construction of a flowchart of relevant scientific questions to which analytical methods are then matched.

On a second methodological point, the effort required to collect so many quadrats was amply rewarded by the number of hypotheses generated and the interesting behaviour observed. It is rare for data collection to be attempted on such a scale. However, counting of annual weed seedlings in a young crop is comparatively quick. Mapping required only 25 person-days each year, with a further 5 days for data entry. It is critical in projects that seek to explore processes and pattern that the sampling regime is done at a scale capable of achieving that aim. Often this does not appear to be the case. Maps constructed from widely-spaced observations by the use of interpolation methods, now common in the weed literature, will be incapable of examining anything but the coarsest-grained processes, such as soil variation. In the case of arable weeds, most dispersal processes including tillage, act primarily over short distances. Strips missed by sprayers are also often very narrow. The important contribution of two-dimensional sampling is that it allows an evaluation of such anisotropy that would otherwise be missed with single transects.

Acknowledgements. We thank Marie-Josée Fortin (University of Toronto) for her advice in the development of this paper, Mike Rosenberg (Arizona State University) for help with his PASSAGE program, and the 19 people who assisted with the data collection. We are indebted to Dennis Jones for his enthusiastic cooperation in the repeated trampling of his crops. Special thanks also go to Lisa Crowfoot for production of the maps and to Frank Forcella (USDA-ARS Soil Conservation Laboratory) for his comments on an earlier version of the manuscript. Lisa Crowfoot and Mohammad Taghizadeh assisted with cover assessment, while Tony Weatherley and Robert Edis gave advice on soil profiles.

\section{References}

Brain, P. \& Marshall, J. 1999. Modelling cultivation effects using fast Fourrier transforms. J. Agric. Biol. \& Environ. Stat. 4: 276-289.

Cousens, R. \& Mortimer, M. 1995. Dynamics of weed populations. Cambridge Universiy Press, Cambridge, UK.

Cousens, R.D., Brown, R., McBratney, A., Whelan, B. \& Moerkerk, M. 2002. Sampling strategy is important for producing weed maps: a case study using kriging. Weed Sci. 50: 542-546.

Cousens, R.D., Wallinga, J. \& Shaw, M.W. 2004. Are the spatial patterns of weeds scale-invariant? Oikos 107: 251264.

Crawley, M.J. 1997. The structure of plant communities. In: Crawley, M.J. (ed.) Plant ecology. 2nd. ed., pp. 475-531. Blackwell Science, Oxford, UK.

Cressie, N.A.C. 1991. Statistics for spatial data. Wiley, New York, NY, US.

Cullinan, V.I. \& Thomas, J.M. 1992. A comparison of quantitative methods for examining landscape pattern and scale. Landscape Ecol. 7: 211-227.

Dale, M.R.T. 1999. Spatial pattern analysis in plant ecology. Cambridge University Press, Cambridge, UK.

Dale, M.R.T. 2000. Lacunarity analysis of spatial pattern: A comparison. Landscape Ecol. 15: 467-478.

Dale, M.R.T. \& Powell, R.D. 2001. A new method for characterizing point patterns in plant ecology. J. Veg. Sci. 12: 597-608.

Dale, M.R.T., Dixon, P., Fortin, M.-J., Legendre, P., Myers, D.E. \& Rosenberg, M.S. 2002. Conceptual and mathematical relationships among methods for spatial analysis. Ecography 25: 558-577.

Dieleman, J.A., Mortensen, D.A., Buhler, D.D., Cambardella, C.A. \& Moorman, T.B. 2000. Identifying associations among site properties and weed species abundance I. Multivariate analysis. Weed Sci. 48: 567-575.

Dunbabin, M.T. \& Cocks, P.S. 1999. Ecotypic variation for seed dormancy contributes to the success of capeweed (Arctotheca calendula) in Western Australia. Aust.J.Agric. Sci. 50: 1451-1458.

Dungan, J., Perry, J.N., Dale, M.R.T., Legendre, P., CitronPousty, S., Fortin, M.-J., Jakomulska, A., Miriti, M. \& Rosenberg, M.S. 2002. A balanced view of scale in spatial statistical analysis. Ecography 25: 626-640.

Fortin, M.-J. \& Dale, M.R.T. 2005. Spatial analysis: A guide for ecologists. Cambridge University Press, Cambridge, UK.

Fotheringham, A.S.\& Zhan, F.B. 1996. A comparison of three exploratory methods for cluster detection in spatial point processes. Geogr. Anal. 28: 200-218.

Green, D.G. 1994. Connectivity and complexity in landscapes and ecosystems. Pac. Conserv. Biol. 1: 194-200.

Howard, C.L., Mortimer, A.M., Gould, P., Putwain, P.D., Cousens, R. \& Cussans, G.W. 1991. The dispersal of weeds: seed movement in arable agriculture.Proc.Brighton Crop Prot. Conf. - Weeds, pp. 664-673. British Crop Protection Council, Thornton Heath, Surrey, UK.

Hurlbert, S.H. 1990. Spatial distribution of the montane uni- 
corn. Oikos 31: 351-357.

Kaluzny, S.P., Vega, S.C., Cardoso, T.P. \& Shelly, A.A. 1998. $S^{+}$Spatial Stats: User's Manual for Windows ' and UNIX'. Springer, New York, NY, US.

Law, R., Purves, D.W., Murrell, D.J. \& Dieckmann, U. 2001. Causes and effects of small-scale spatial structure in plant populations. In: Silvertown, J. \& Antonovics, J. (eds.) Integrating ecology and evolution in a spatial context, $\mathrm{pp}$. 21-44. Blackwell Science, Oxford, UK.

Legendre, P. \& Legendre, L. 1998. Numerical ecology. 2nd. English ed. Elsevier, Amsterdam, NL.

May, R.M.(ed.) 1981. Theoretical ecology. 2nd. ed. Blackwell Scientific, Oxford, UK.

McNeill, J.D. 1992. Rapid, accurate mapping of soil salinity by electromagnetic ground conductivity meters. In: $A d$ vances in measurements of soil physical properties: Bringing theory into practice. Soil Science Society of America Special Publication 30, ASA, CSSA, and SSSA, Madison, WI, US.

Mead, A., Grundy, A.C., Brain, P. \& Marshall, E.J.P. 2003. Development of a model for the joint horizontal and vertical movement of seeds following cultivation. Aspects Appl. Biol. 69, Seedbanks: Determination, dynamics and management, pp. 179-186. Association of Applied Biologists, Wellesbourne, Warwickshire, UK.

Medd, R.W. 1996. Ecology of wild oats. Plant Prot. Q. 11 (suppl. 1): 185-187.

Moerkerk, M.R. 2002. Seed box survey of field crops in Victoria during 1996 and 1997. In: Jacob, H.S., Dodd, J. \& Moore, J.H. (eds.) Proc. 13th. Aust. Weeds Conf., Perth, 8-13 September 2002, pp. 55-58. R.G. \& F.J. Richardson, Meredith, VIC, AU.

Murrell, D.J. \& Law, R. 2003. Heteromyopia and the spatial coexistence of similar competitors. Ecol. Lett. 6: 48-59.

Musick, H.B. \& Grover, H.D. 1991. Image textural measures as indices of landscape pattern. In: Turner, M.G. \& Gardner, R.H. (eds.) Quantitative methods in landscape ecology: The analysis and interpretation of landscape heterogeneity, pp. 77-103. Springer, New York, NY, US.

Paice, M.E.R., Day, W., Rew, L.J. \& Howard, A. 1998. A stochastic simulation model for evaluating the concept of patch spraying. Weed Res. 38: 373-387.

Perry, J.N., Liebhold, A.M., Rosenberg, M.S., Dungan, J., Miriti, M., Jakomulska, A. \& Citron-Pousty, S. 2002. Illustrations and guidelines for selecting statistical methods for quantifying spatial pattern in ecological data. Ecography 25: 578-600.

Pielou, E.C. 1977. Mathematical ecology. Wiley, New York, NY, US.

Purves, D.W. \& Law, R. 2002. Fine-scale spatial structure in a grassland community: quantifying the plant's-eye view. $J$. Ecol. 90: 121-129.

Rew,L.J. \& Cousens, R.D. 2001. Spatial distribution of weeds in arable crops: are current sampling and analytical methods appropriate? Weed Res. 41: 1-18.

Rew, L.J. \& Cussans, G.W. 1997. Horizontal movement of seeds following tine and plough cultivation: implications for spatial dynamics of weed infestations. Weed Res. 37: 247-256.
Rice, K. J. 1985. Responses of Erodium to varying microsites: the role of germination cueing. Ecology 66: 1651-1657.

Ridge, P.E. 1986. A review of long fallows for dryland wheat production in southern Australia. J. Aust. Inst. Agric. Sci. 52: 37-44.

Shaw, M.W. 1995. Simulation of population expansion and spatial pattern when individual dispersal distributions do not decline exponentially with distance. Proc. $R$. Soc. Lond. B 259: 243-248.

Shigesada, N. \& Kawasaki, K. 1997. Biological invasions: theory \& practice. Oxford University Press, Oxford, UK.

Skellam, J.G. 1951. Random dispersal in theoretical populations. Biometrika 38: 196-218.

Southwood, T.R.E. 1966. Ecological methods with particular reference to the study of insect populations. Methuen, London, UK.

Stamp, N.E. 1989. Seed dispersal of four sympatric grassland annual species of Erodium. J. Ecol. 77: 1005-1020.

Stephens, P.A., Sutherland, W.J. \& Freckleton, R. 1999. What is the Allee effect? Oikos 87: 185-190.

Tilman, D. \& Karieva, P. (eds.) 1997. Spatial ecology: The role of space in population dynamics and interspecific interactions. Princeton University Press, Princeton, NJ, US.

Upton, G.J.G. \& Fingleton, B. 1985. Spatial data analysis by example. Vol. 1. Point pattern and quantitative data. Wiley, New York, NY, US.

Wallinga, J. 1995. The role of space in plant population dynamics: annual weeds as an example. Oikos 74: 377383.

Walsh, N.G. \& Entwisle, T.J. (eds.) 1994-1999. Flora of Victoria. Vols. 2-4. Inkata Press, Melbourne, AU.

Webster, R. \& Oliver, M. 2001. Geostatistics for environmental scientists. Wiley, Chichester, UK.

Wiegand, K., Jeltsch, F. \& Ward, D. 2000. Do spatial effects play a role in the spatial distribution of desert-dwelling Acacia raddiana? J. Veg. Sci. 11: 473-484.

Wiles, J. \& Brodahl, M. 2004. Exploratory data analysis to identify factors influencing spatial distributions of weed seed banks. Weed. Sci. 52: 936-947.

Wilson, B.J. \& Brain, P. 1991. Long-term stability of distribution of Alopecurus myosuroides Huds. within cereal fields. Weed Res. 31: 367-373.

Received 19 May 2005;

Accepted 1 June 2006; Co-ordinating Editor: P. Dixon.

For Apps. 1 and 2, see JVS/AVS Electronic Archives; www.opuluspress.sel 


\section{University Library}

\section{- M M N E R VA A gateway to Melbourne's research publications}

Minerva Access is the Institutional Repository of The University of Melbourne

\section{Author/s:}

Cousens, Roger D.;Dale, Mark R. T.;TAYLOR, JAMES;Law, Richard;Moerkerk, Michael;Kembel, Steven W.

Title:

Causes of pattern in plant communities where environmental change is rapid and species longevity is short

Date:

2006

Citation:

Cousens, R. D., Dale, M. R. T., Taylor, J., Law, R., Moerkerk, M., \& Kembel, S. W. (2006). Causes of pattern in plant communities where environmental change is rapid and species longevity is short. Journal of Vegetation Science, 17(5), 509-524.

Publication Status:

Published

Persistent Link:

http://hdl.handle.net/11343/34648 